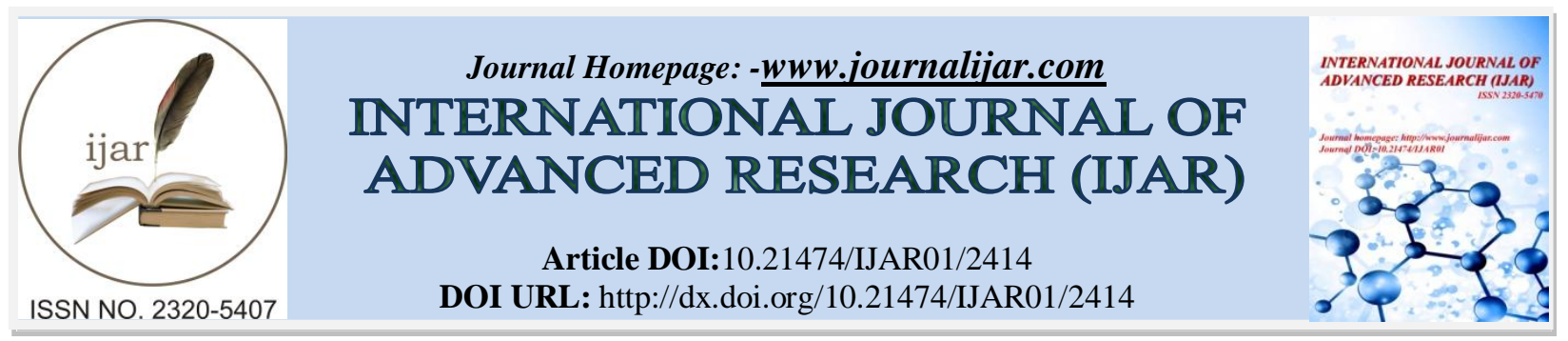

RESEARCH ARTICLE

\title{
THE PREVENTABLE CAUSES RELATED OF INTRAUTERINE FETAL DEATH IN KING ABDULAZIZ UNIVERSITY HOSPITAL, JEDDAH.
}

\author{
Ayman A Bukhari ${ }^{1}$, WajdAyidAlotaibi ${ }^{2}$, Fai Ali Alotaibi ${ }^{3}$, MuneeraAbdurahmanSattam ${ }^{3}$ and Osama S \\ Bajouh $^{4}$. \\ 1. SBOG,ABOG, Assistant Professor-OB/Gyn department King Abdulaziz University, Jeddah, Saudi Arabia. \\ 2. Medical intern - King Abdulaziz University - Jeddah - Saudi Arabia. \\ 3. Medical students - King Abdulaziz University - Jeddah - Saudi Arabia. \\ 4. SBOG,AFSA Assistant Professor-OB/Gyn department King Abdulaziz University - Jeddah - Saudi Arabia.
}

\section{Manuscript Info}

Manuscript History

Received: 20 October 2016

Final Accepted: 22 November 2016

Published: December 2016

Key words:-

Intrauterine fetal death (IUFD), maternal and fetal risk factors.

\section{Abstract}

Background: -Intrauterine fetal death (IUFD) is a depressing event for the families and their doctors. This study aimed to determine associated maternal and fetal risk factors to IUFD.

Method:- This retrospective study included all IUFD cases admitted to the emergency room and OB/ GYN department at King Abdulaziz University Hospital from January, 2015 to May, 2016.

Result:- The study enrolled 120 IUFD cases, with mean maternal age $32.8+6.57$, gestational age mean score $32.03+6.54,25(20.3 \%)$ cases reported medical history. More than third (44- 36.7\%) reported antenatal care (ANC) services, and only14 (11.7\%) cases reported previous IUFD.In $70(58.3 \%)$ cases absent fetal heart beat was recorded $44(36.7 \%)$ cases absent fetal movement was recorded .Almost the half of the cases $(59-49.2 \%)$ reported induction of labor.ER admission recorded $110(91.7 \%)$ cases .Placenta was sent to histopathology in the majority of cases (104-86.7\%).

Conclusion:- Several factors were associated with IUFD cases, most of them are preventable if there is good ANC, there is need for more campaigns and educational programs to increase the level of awareness about the benefits of ANC.

Copy Right, IJAR, 2016,. All rights reserved

\section{Introduction:-}

The rate of child mortality is one of the important indicatorsof countriesdevelopment, most of the deaths occurred during perinatal period as stillbirth after the 22th week of pregnancy and during neonatal period (first 4 weeks of life). $(1,2)$ Intrauterine fetal death (IUFD) is a distressing situation for the caregiver and a traumatic event for the family. IUFD definition includes antepartum deaths beyond 20 weeks of gestation and birth weight $>500 \mathrm{gm}$, there are variety between studies about the gestational age which stillbirth are considered.(3)The rate of IUFD calculated as the number of IUFD per 1000 deliveries. (3,4)Intrauterine fetal death may be antepartum or intrapartum. Antepartum fetal deaths are associated with several maternal, placental or fetal factors. Hypertensive disorders of pregnancy, anemia, obesity, diabetes, high parity, advanced maternal age are well recognized maternal factors, and placental pathology such as abruption placenta, whereas congenital anomalies, intrauterine growth retardation, severe fetal growth restriction (FGR) or cord accident are important fetal factors . $(3,5,6)$ Even that 
several conditions have been linked to stillbirth, it is difficult to define the precise etiology in many cases.(7)Several studies indicated the unexplained fetal deaths, these deaths occur in late pregnancies and sometimes even in women with regular antenatal care. $(6,8)$

The rate of stillbirth around the world recorded as 3 million which $70 \%$ of theses problems happened in the developing countries in Asia and sub Saharan Africa together due to several reasons such as: lack of prenatal care and inaccessible or limited health care facilities. Which is the major factor responsible for high perinatal deaths in these regions, $(3,7)$ while stillbirth in developed countries is largely ante-partum with no apparent cause.(9)

The proper and good antenatal care (ANC)could help in reducing stillbirths cases due to the early diagnosis of maternal health problems ( which affect both mother and fetus) and giving the suitable treatment. Furthermore, early and suitable ANC helps in preparing pregnant women to be aware of labor signs and delivery difficulties, also it encourage them to look for a good obstetric care during labor, which could help to avoid intrapartum stillbirths (10). Several studies indicated that having early ANC could avoid stillbirths in termpregnancies by dealing with labor complications through early referral to qualified Obstetrician-Gynecologist, and/or by identifying and treating maternal problems. $(10,11)$

This study aimed to determine associated maternal and fetal risk factors to IUFD in King Abdulaziz University Hospital in Jeddah, Saudi Arabia.

\section{Method:-}

This retrospective study included all pregnant women who diagnosedIUFD and admitted to the emergency room (ER) and OB/ GYN department at King Abdulaziz University Hospital (KAUH), a large tertiary public hospital in Jeddah, Saudi Arabia, between January, 2015, and May, 2016. Institutional ethical approval was received. The Inclusion criteria were singleton IUFD with fetal weight $1000 \mathrm{gm}$ and more, while all cases with multiple pregnancy were excluded. The criteria of IUFD diagnosis was absent fetal heart sounds and an ultrasonography confirmation. All the information was obtained from clinical notes, hospital files and admissionbook. Data was classified as : sociodemographic data (age, nationality, educational level, occupation and smoking habit), obstetrics history (gravidity, parity, gestational age, abortion ,C/S history, previous IUFD, pregnancy complications , hypertensive, GDM \&ANC services), medical history (blood type , DM, hypertension, thyroid, epilepsy, surgical history, cancer, radiotherapy and drugs history), presenting illness (pain, bleeding, leaking of fluid \& labor), management (regular visit and follow up, labor induction, labor hours ,C/S type, blood transfusion, admission type and hospitalization duration ), fetus section (delivery type, birth weight \& gender), ultrasound findings (absent fetal heartbeat, absent fetal movement, Spalding sign, maceration) and laboratory investigation (hemoglobin concentration, platelet count, white blood cell count and placenta histopathology) .

The collected data were analyzed using the SPSS statistical software package, version 20. Parametric data are expressed as mean and standard deviations (minimum and maximum) and non-parametric data are expressed as number (percentage).

\section{Result:-}

During the period of study there are120 cases of IUFD admitted to KAUH, of which $56(46.7 \%)$ were Saudi \& 64 $(53.3 \%)$ were non-Saudi, with mean age score 32.8+6.57 rang (18-47), around third (27.5\%) were from group age more than 35 years and more than half $(56.7 \%)$ from group age 26-35 years. Less than third (29- 24.2\%) reported as first parity (first pregnant) with gravidity mean score4.0 \pm 2.0 rang (0-12) and gestational age mean score 32.03+6.54 rang (20-41)weeks, more than half (54.2\%) were from GA group less than 34 weeks (preterm), while third of the cases(35.6\%) from GA group 37-40 weeks (term). Only 13 (10.8\%) cases reported regular visits, 25 (20.8\%) recorded pain and $23(19.2 \%)$ bleeding. Decreased fetal movement was reported in $33(27.7 \%)$ while Leaking of fluid was reported in $5(4.2 \%)$ cases and only in $2(1.7 \%)$ cases (Womb that fails to get bigger over time) was stated.(Table 1\& Figure 1) 
Table 1:-Demographic data \& Presenting illness.

\begin{tabular}{|l|l|}
\hline Demographic $(\mathrm{N}=120)$ & \\
\hline Age & $\mathbf{3 2 . 8} \pm \mathbf{6 . 5 7}(\mathbf{1 8 - 4 7})$ \\
\hline Gravidity & $\mathbf{4 . 0} \pm \mathbf{2 . 8 2}(\mathbf{0 - 1 2})$ \\
\hline Gestational age(weeks) & $\mathbf{3 2 . 0 3} \pm \mathbf{6 . 5 4}(\mathbf{2 0 - 4 1 )}$ \\
\hline Parity & \\
\hline Prime & $29(24.2 \%)$ \\
\hline Multiparous & $91(75.8 \%)$ \\
\hline Smoking & $\mathbf{3}(\mathbf{2 . 5 \%})$ \\
\hline Gestational agegroup & \\
\hline less than 34 & $64(54.2 \%)$ \\
\hline 34-37 & $11(9.3 \%)$ \\
\hline 37-40 & $42(35.6 \%)$ \\
\hline more than 40 & $1(0.8 \%)$ \\
\hline Presenting illness (N=120) & \\
\hline Regular visit & $\mathbf{1 3}(\mathbf{1 0 . 8 \%})$ \\
\hline Pain & $\mathbf{2 5}(\mathbf{2 0 . 8 \%})$ \\
\hline Bleeding & $\mathbf{2 3 ( 1 9 . 2 \% )}$ \\
\hline Decreased fetal movement & $\mathbf{3 3 ( 2 7 . 7 \% )}$ \\
\hline Leaking of fluid & $\mathbf{5 ( 4 . 2 \% )}$ \\
\hline Womb that fails to get bigger over time & $\mathbf{2 ( 1 . 7 \% )}$ \\
\hline
\end{tabular}

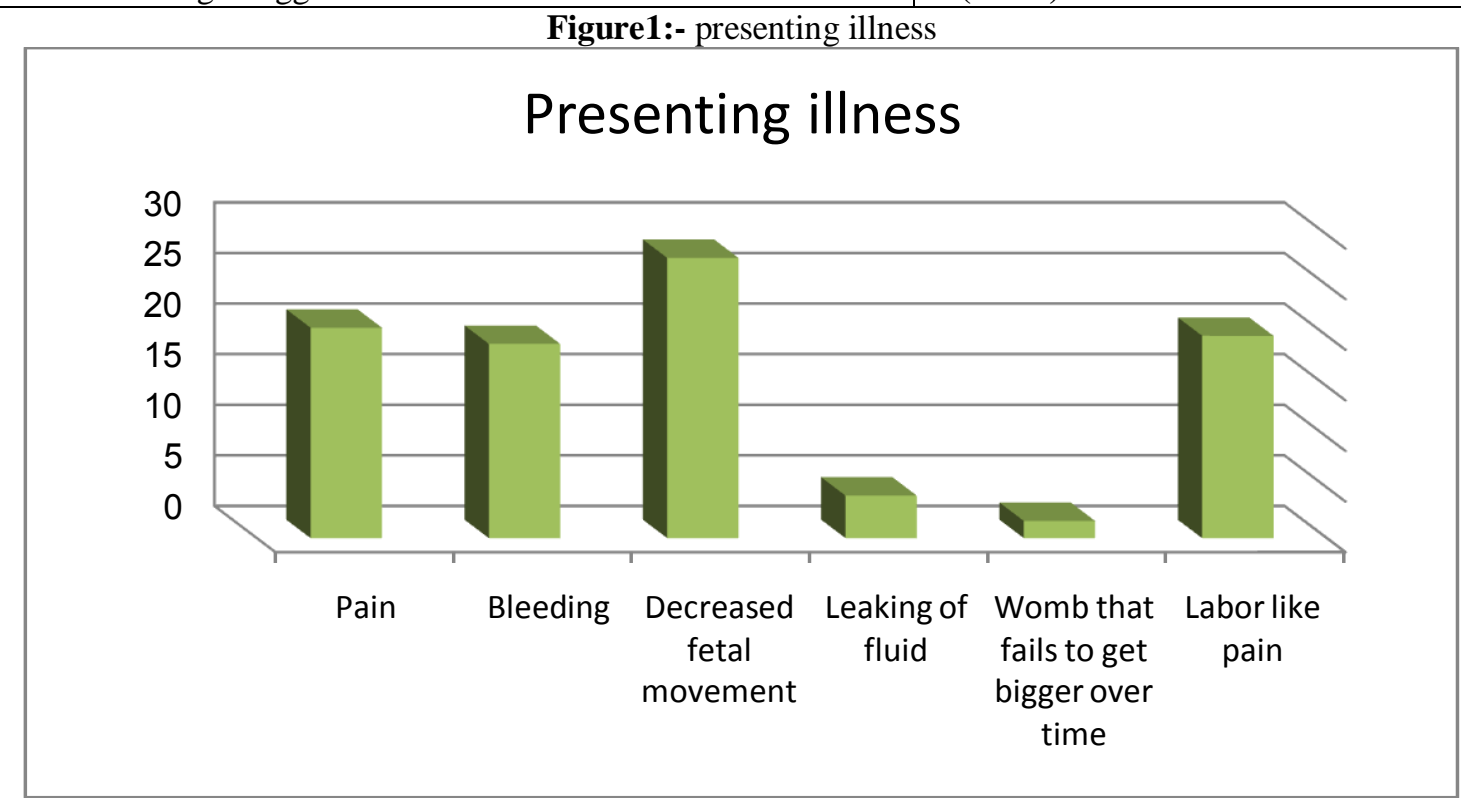

From the total 120 women $17(14.2 \%)$ reported as surgical history and $25(20.3 \%)$ had medical history, 9 (7.5\%) DM, followed by $5(4.2 \%)$ thyroid diseases and 5 (4.2\%) blood group incompatibility equally. More than third (44$36.7 \%$ ) reported ANC services, from these cases 22 had ANC services from 1st trimester, 12 at 2nd trimester and only 7 at 3rd trimester. During pregnancy $13(10.8 \%)$ cases had GDM, $28(23.3 \%)$ cases had hypertensive disorder. From the total 120 cases $14(11.7 \%)$ cases reported previous IUFD ,38 (31.7\%) cases reported previous abortion and $37(30.8 \%)$ cases reported previous C/S . abruption placenta was recorded in 7 cases and placenta previa in 5 cases while the majority (94-78.3\%) reported no Antepartum hemorrhage . (Table 2\& figures 2,3\&4). 
Table 2:-Past medical history \& Obstetrics history.

\begin{tabular}{|c|c|}
\hline Past medical history $(\mathrm{N}=25)$ & \\
\hline $\mathrm{DM}$ & $9(36.0 \%)$ \\
\hline Thyroid disease & $5(20.0 \%)$ \\
\hline Blood group incompatibility & $5(20.0 \%)$ \\
\hline \multicolumn{2}{|l|}{ Obstetrics history $(\mathrm{N}=120)$} \\
\hline Post term pregnancy $(\mathrm{N}=120)$ & $2(1.7 \%)$ \\
\hline pregnant by IVF & $2(1.7 \%)$ \\
\hline ANC services & $44(36.7 \%)$ \\
\hline \multicolumn{2}{|l|}{ Gestational age at first ANC visit } \\
\hline Not applicable & $79(65.8 \%)$ \\
\hline 1st trimester & $22(18.3 \%)$ \\
\hline 2nd trimester & $12(10.0 \%)$ \\
\hline 3rd trimester & $7(5.8)$ \\
\hline Hypertensive disease in pregnancy & $28(23.3 \%)$ \\
\hline Gestational diabetes mellitus & $13(10.8 \%)$ \\
\hline previous IUFD & $14(11.7 \%)$ \\
\hline History of abortion & $38(31.7 \%)$ \\
\hline History of $\mathrm{C} / \mathrm{S}$ & $37(30.8 \%)$ \\
\hline
\end{tabular}

Figure 2:-Pregnancy diseases.

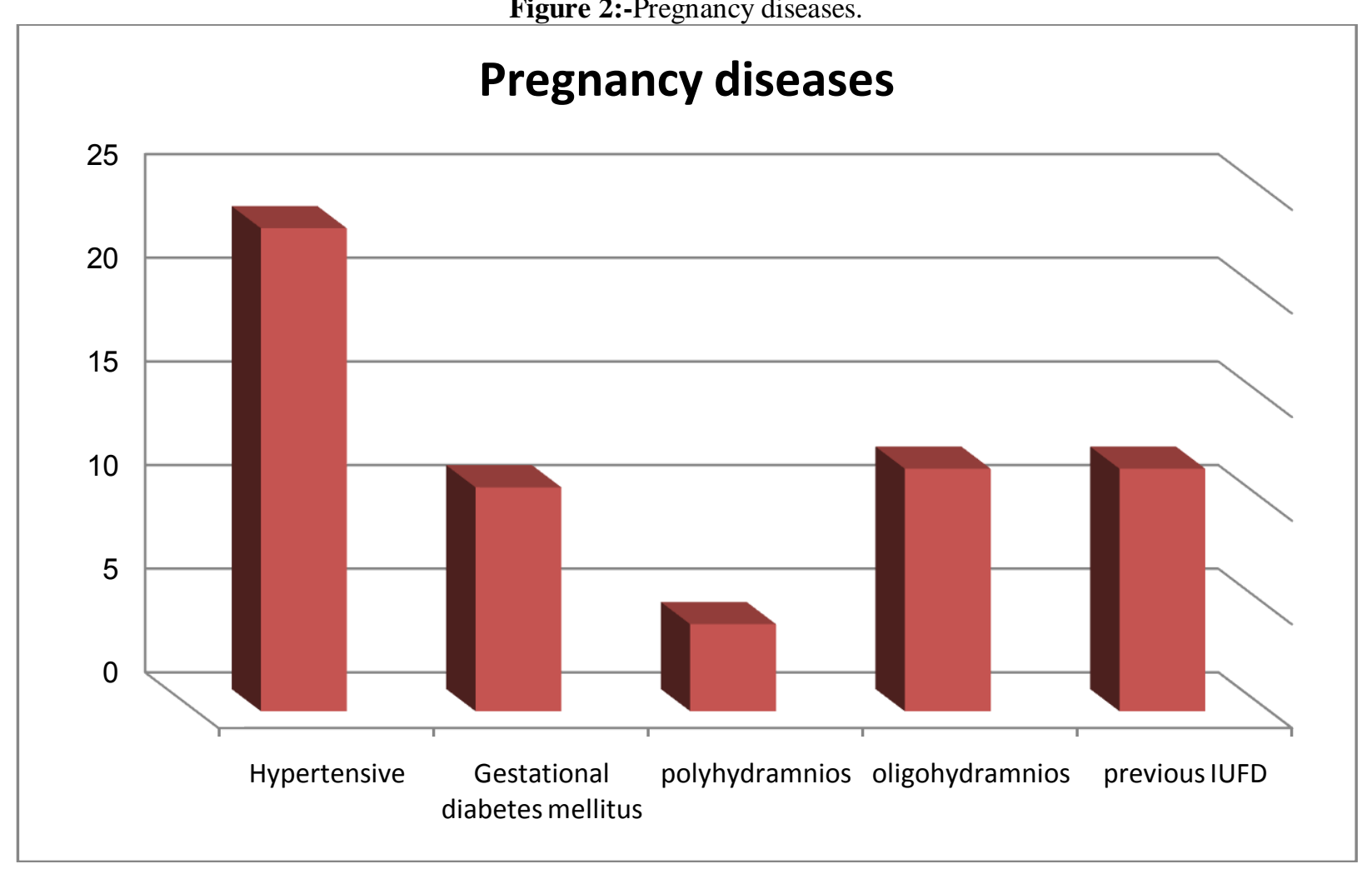


Figure3:-Number of abortion.

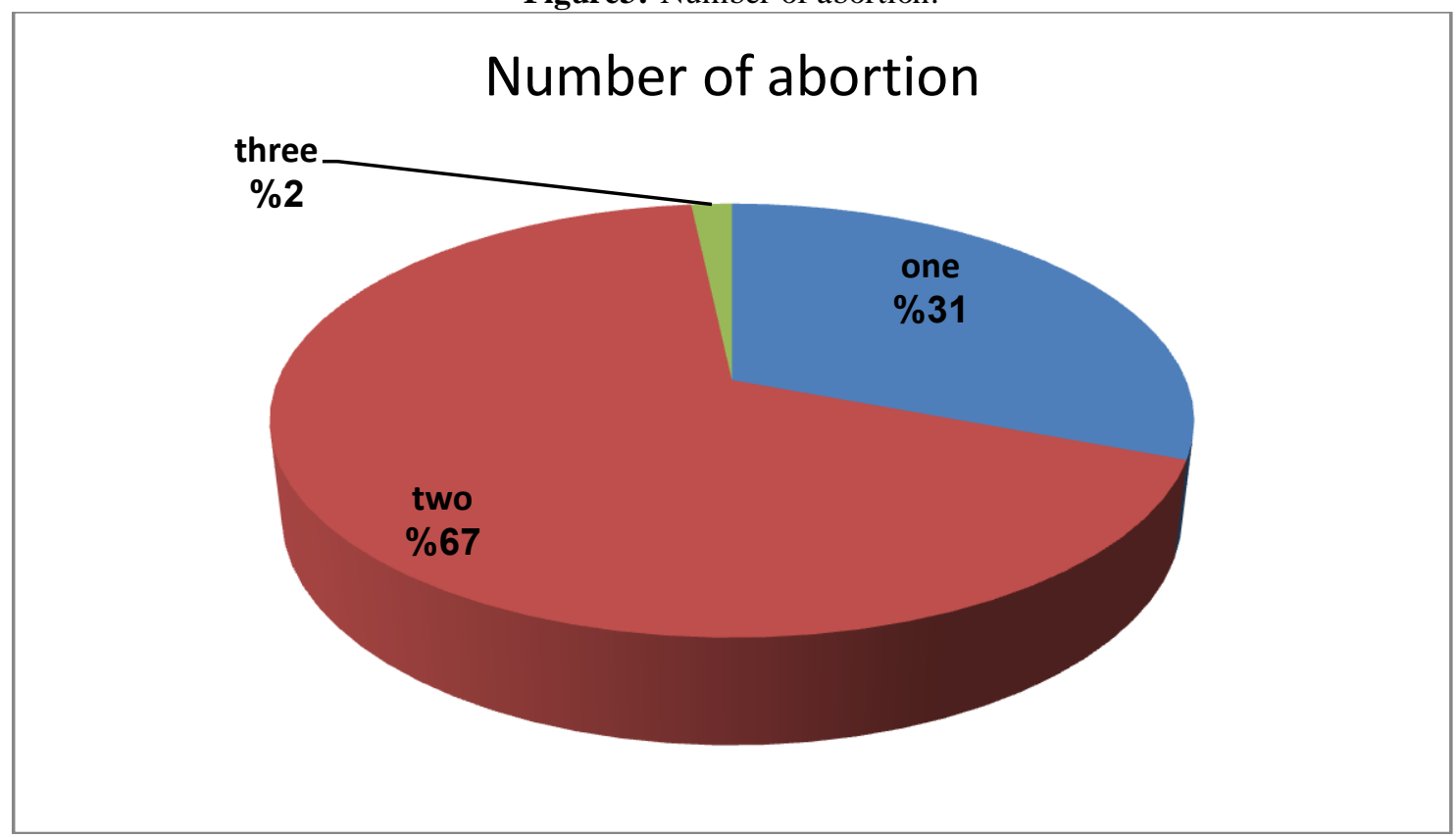

Figure 4:-Number of C/S.

\section{Number of $\mathrm{C} / \mathrm{S}$}

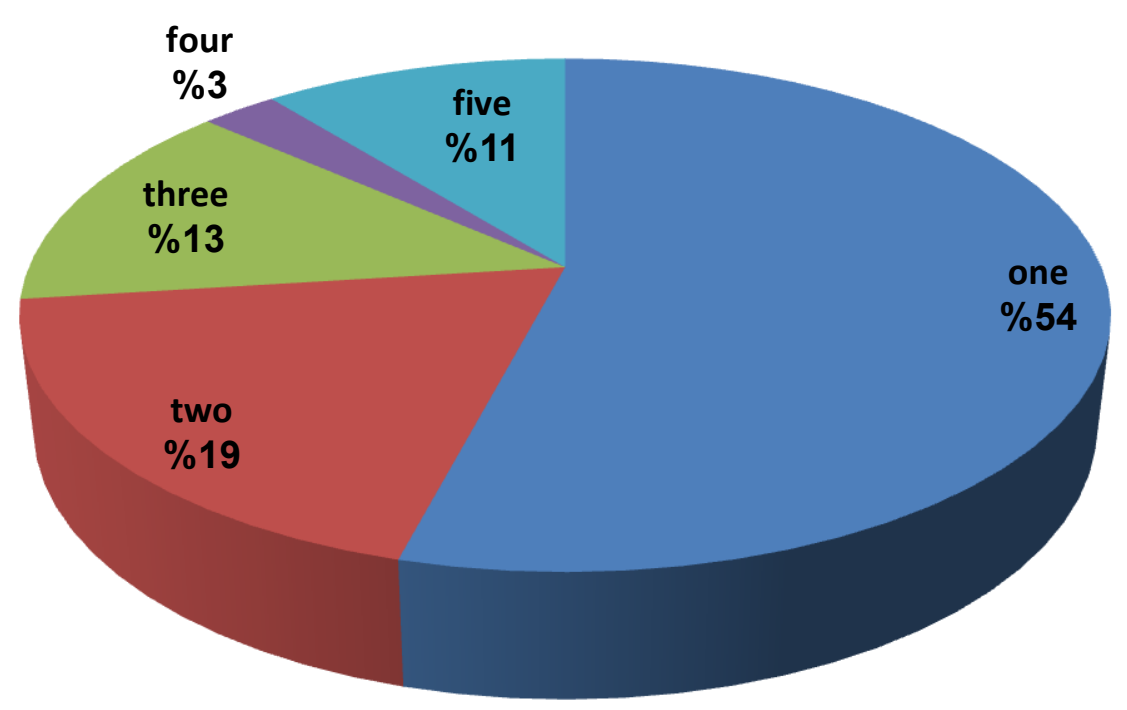


Regarding ultrasound findings, almost two third (77-64.2\%) performed it, in 70 (58.3\%) cases absent fetal heart beat was recorded and $44(36.7 \%)$ cases absent fetal movement wererecorded. Only 6 cases (Spalding sign) were reported and 4 cases (maceration) were reported. Soft tissue edema was stated in $14(11.7 \%)$ cases .Thrombus in fetal heart and gas shadow in fetal heart (Robert's sign) were not reported in $79(65.8 \%)$ cases while the rest (41$34.2 \%$ ) reported as not applicable.Oligohydramnios was reported in $14(11.7 \%)$ cases and only $5(4.2 \%)$ cases reported polyhydramnios. Concerning management, almost half of the cases $(59-49.2 \%)$ reported induction of labor, followed by C/S (34-28.3) then expectant management was (25-20.8\%). The majority of cases ( 84- 70.0\%) recorded SVDwhile in $20(16.7 \%)$ cases were reported as emergency C/S and $13(13.3 \%)$ cases reported as C/S elective, with mean score of hospitalization 5.0 \pm 2.0 rang (2-11) days . Only in $8(6.7 \%)$ cases blood transfusion was done. $110(91.7 \%)$ cases were admitted through ER. The majority of cases (99-82.5\%) reported no postpartum complications. (Table 3 Figures5 \& 6).

Table 3:-Ultrasound findings \& Management.

\begin{tabular}{|l|l|}
\hline Ultrasound findings $(\mathrm{N}=120)$ & \\
\hline Absent fetal heart beat & $\mathbf{7 0}(\mathbf{5 8 . 3 \%})$ \\
\hline Absent fetal movement & $\mathbf{4 4}(\mathbf{3 6 . 7 \%})$ \\
\hline Overlapping of skull bones (Spalding sign) & $\mathbf{6}(\mathbf{5 . 0 \%})$ \\
\hline Gross distortion of fetal anatomy (maceration) & $\mathbf{4}(\mathbf{3 . 3 \%})$ \\
\hline Soft tissue edema: skin>5mm & $\mathbf{1 4}(\mathbf{1 1 . 7 \%})$ \\
\hline polyhydramnios & $\mathbf{5}(\mathbf{4 . 2 \%})$ \\
\hline oligohydramnios & $\mathbf{1 4}(\mathbf{1 1 . 7 \%})$ \\
\hline Management $\mathrm{N}=120)$ & \\
\hline Type of delivery & \\
\hline SVD & $84(70.0 \%)$ \\
\hline C/S ER & $20(16.7 \%)$ \\
\hline C/S ELECTIVE & $16(13.3 \%)$ \\
\hline Blood transfusion & $\mathbf{8 ( 6 . 7 \% )}$ \\
\hline Type of admission & \\
\hline ER & $110(91.7 \%)$ \\
\hline Clinic & $10(8.3 \%)$ \\
\hline Number of days in hospital & $\mathbf{5 . 0 \pm 2 . 0 ( 2 - 1 1 )}$ \\
\hline
\end{tabular}


Figure5:-Ultrasound findings.

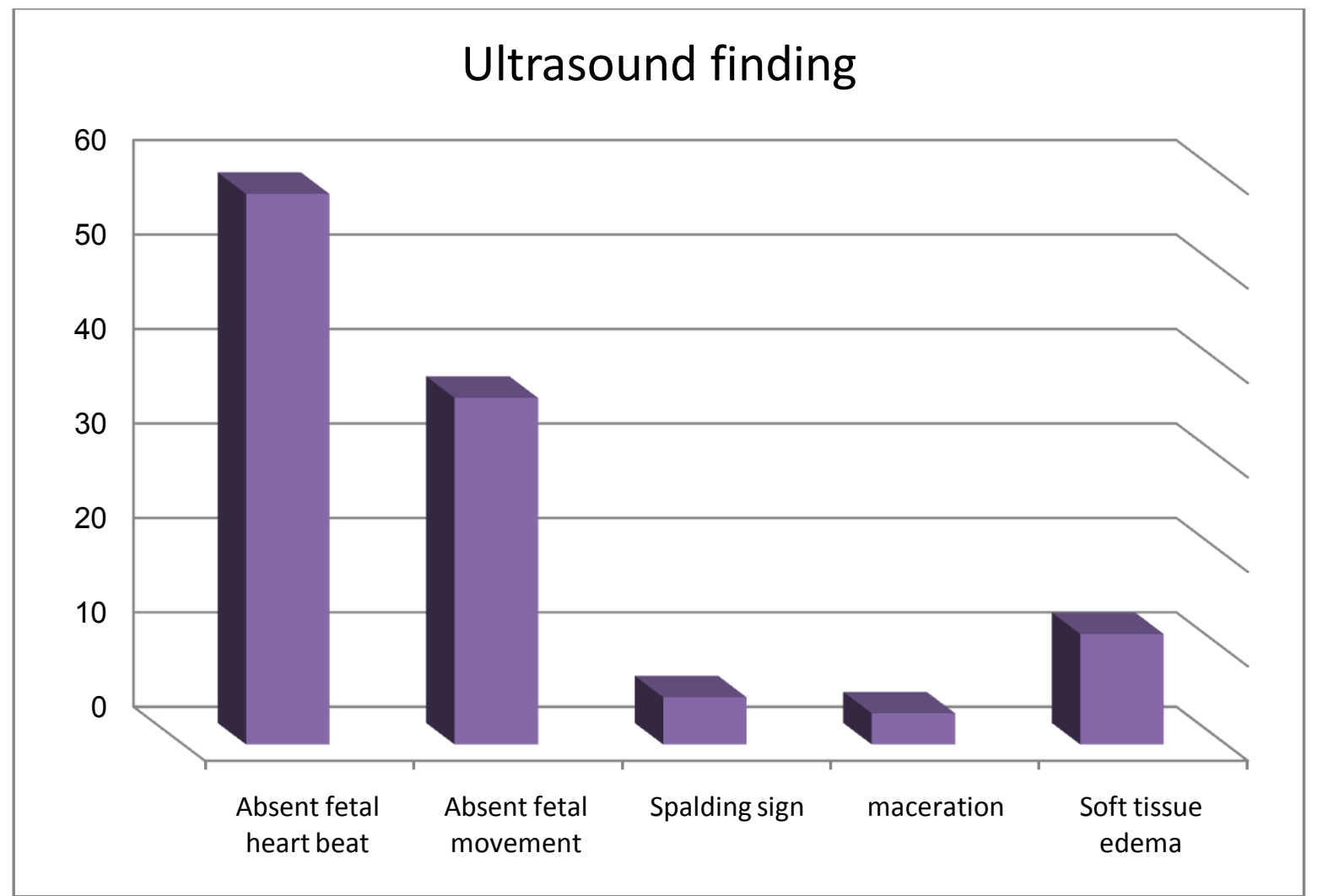

Figure 6:-Management

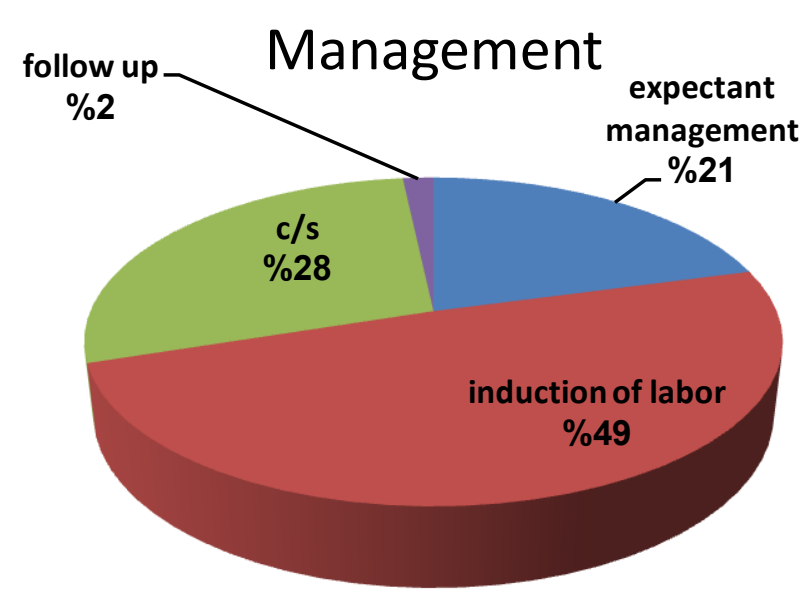

Regarding fetal information, TFT was normal in 27 (22.5\%) cases and abnormal in $12(10.0 \%)$, placenta was sent to histopathology in the majority of cases (104-86.7\%). Infections work up was normal in 27 (22.5\%) and abnormal in $48(40.0 \%)$, while in $25(20.8 \%)$ cases diabetes work up was reported. IUGR was reported in $6(5.0 \%)$ cases, fetal umbilical cord complications was reported in $3(2.5 \%)$ cases, fetal major anomalies was reported in $12(10.0 \%)$ cases , genetic abnormality was reported in $1(0.8 \%)$ case , and Hydropsfetaliswas reported in $5(4.2 \%)$ cases. Only in 2 cases $(1.7 \%)$ Pregnant by IVF was recorded. In more than two third of the cases (84-70.0\%) Hemoglobin concentration was $=<12.2$ and White blood cells count was 4500-11500, while the majority of cases (101- 84.2\%) Platelet count was150000-450000.ANA examination was positive in $10(8.3 \%)$ cases and negative in 31 (25.8\%) 
cases, while LAC examination was positive in $4(3.3 \%)$ cases and negative in $33(27.5 \%)$ cases. (Table4\& Figure 7).

Table 4:-Fetus section \& Laboratory investigation.

\begin{tabular}{|c|c|}
\hline Fetus section $(\mathrm{N}=120)$ & \\
\hline IUGR & $6(5.0 \%)$ \\
\hline Fetal umbilical cord complications & $3(2.5 \%)$ \\
\hline Fetal major anomalies & $12(10.0 \%)$ \\
\hline Genetic abnormality & $1(0.8 \%)$ \\
\hline Hydrops fetalis & $5(4.2 \%)$ \\
\hline \multicolumn{2}{|l|}{ Laboratory investigation $(\mathrm{N}=120)$} \\
\hline \multicolumn{2}{|l|}{ TFT } \\
\hline Normal & $27(22.5 \%)$ \\
\hline Abnormal & $12(10.0 \%)$ \\
\hline Not done & $81(67.5 \%)$ \\
\hline Placenta to histopathology & $104(86.7 \%)$ \\
\hline \multicolumn{2}{|l|}{ Infections work up } \\
\hline Normal & $27(22.5 \%)$ \\
\hline Abnormal & $48(40.0 \%)$ \\
\hline Not done & $45(37.5 \%)$ \\
\hline Diabetes work up & $25(20.8 \%)$ \\
\hline \multicolumn{2}{|l|}{ Hemoglobin concentration } \\
\hline $12.3-15.3$ & $34(28.3 \%)$ \\
\hline$=<12.2$ & $84(70.0 \%)$ \\
\hline Unknown & $2(1.7 \%)$ \\
\hline \multicolumn{2}{|l|}{ White blood cells count } \\
\hline $4500-11500$ & $84(70.0 \%)$ \\
\hline$\Rightarrow 11501$ & $32(26.6 \%)$ \\
\hline$=<4499$ & $2(1.7 \%)$ \\
\hline Unknown & $2(1.7 \%)$ \\
\hline \multicolumn{2}{|l|}{ ANA $(\mathrm{N}=41)$} \\
\hline$+\mathrm{ve}$ & $10(24.4 \%)$ \\
\hline$-\mathrm{ve}$ & $31(75.6 \%)$ \\
\hline \multicolumn{2}{|l|}{ LAC $(\mathrm{N}=37)$} \\
\hline$+\mathrm{ve}$ & $4(10.8 \%)$ \\
\hline$-\mathrm{ve}$ & $33(89.2 \%)$ \\
\hline
\end{tabular}


Figure 7:-Postpartum complications.

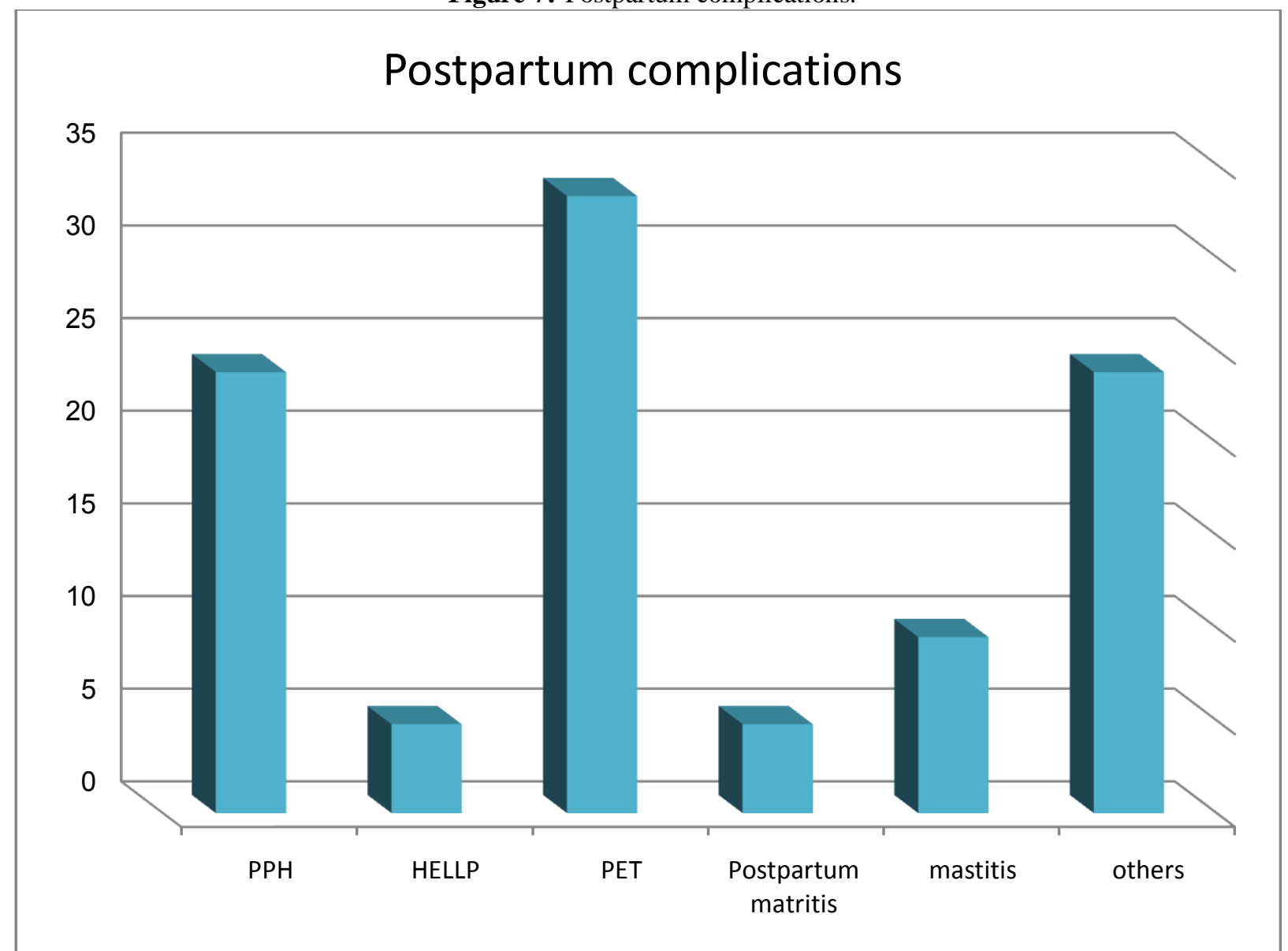

\section{Discussion:-}

There is varietyin rates of IUFD cases between countries and even between cities in the same country, this difference could be due to several factors. One of them is the difference in determining the gestational age and weight of the fetus in the definition of IUFD, other factor is the level and quality of antenatal care service. $(3,8)$ In the study conduct 2014 in Ethiopia the authors reported similar results to the previous studies that the rate of death in early neonatal period are more than the rate of death in late neonatal period by 4 times, and they linked that to the all other factors related to pregnancy, delivery and neonatal care period , (2) due to that several studies were conducted to determine the risk factors associated with prenatal mortality, these factors could be due to maternal, placental or fetal factors such as poor antenatal care, prim gravidity, preterm delivery, low birth weight , maternal age and health condition ( GDM \& hypertension) . $(8,12)$

Regarding maternal factors associated with stillbirth, in the current study more around third of the cases were from group age more than 35 ,several studies demonstrated the relation between maternal age and stillbirth as showed its impact on other risk factors , childbearing women before 20 and after 40 years are more likely to have stillbirth than women in group age 24-35 years and this problem are doubled and more clear in women aged $\geq 40$ years, $(13,14)$ as what mentioned in other studies maternal age have relation with gestational age and birth weight, women aged less than 20 years are more likely to develop SGA( small in gestational age) while women aged more than 40 years are more likely to have S/C and macrocosmic neonate. $(14,15)$

Maternal body mass index ( BMI) reported in several studies as risk factor for IUFD, it was reported that obese women comparing with normal weight women have the chance to develop more complication during pregnancy and delivery and they indicate that to their ability to develop hypertensive and diabetes mellitus, and in the majority of the cases they deliver S/C , $(14,15)$ also in the study conducted--- the authors demonstrated the negative relation between BMI and placental taurine transporter activity when maternal BMI increased this induced decreasing in fetal placental weight ratio (representing placental efficiency). (16) 
In the study conduct 2014 in China the authors reported that advanced maternal age and obesity work together to increase the risk of stillbirth and they indicated to the need for intense nutritional control from the early week of pregnancy to reduce the rate of perinatal mortality and morbidity. $(14,15)$ Several studies reported that more than $10 \%$ of IUFD cases related to maternal illness such as diabetes, hypertension ( either chronic or pre-eclampsia), thyroid, infection diseases and Antepartum hemorrhage, the result of current study consistence with other studies results $(10.8 \%$ GDM \&23.3\% hypertension), $(8,17)$ in the current study previous IUFD was reported in $11.8 \%$ of the cases and 10\% Fetal major anomalies which consistence with other studies finding and indicate genetic or chromosomal problems . (8)

Umbilical cord \& placental complications are important risk factors associated with IUFD, nuchal cord in $23 \%$ of the cases and $1 \%$ of true umbilical knots associated with $2.7 \%$ of death cases due to obstructed fetal blood flow, and they stated the need for pathological anatomy examination to identify the findings and the if knot or nuchal cord are the real cause of death, in the case of abnormal inserting of umbilical cord to placental this could induce rupture or inflammation and cause Placental abruption which is fetal in $0.12 \%$ of the cases and presents as bleeding and abdominal pain , in the current study only 3 cases (2.5\%) reported fetal umbilical cord complications (looping, knotting, twisting) and in $86.7 \%$ of the cases placental was sent to histopathology . $(15,18)$

Intrauterine growth restriction (IUGR) is the biggest risk factor aftercongenital anomalies factor cause perinatal death fetuses, evaluation of umbilical cord and placental could help in diagnosis IUGR causes (maternal and fetal vascular injuries, placental developmental abnormalities or inflammatory lesions), in the current study only 6 cases $(5.0 \%)$ recorded as IUGR. (19)

Several studies were carried out and stated that The majority of the previous risk factors are preventable and could be avoided by good level antenatal care (ANC), by receiving good level of care a lot of factors could be under controlled ( blood sugar level, blood pressure ), congenital anomalies could be discovered earlier, prescribe folic Acid, referral women to good center for $\mathrm{C} / \mathrm{S}$ section provide a specialized care for high risk cases,$(8,10)$ in the current study 44 cases $(36.7 \%)$ received ANC. In Ethiopia study the authors reported difference in the rate of IUFD cases between urban \& rural areas due to the variety in ANC care , (2) in the study conduct 2015 the authors reported that $38 \%$ of the IUGR cases didn't receive any antenatal care ( no booking, didn't response to fetal absent movement ) (20) , in South African study 2015 the authors stated that managing intrapartum asphyxia, hypertensive disorders and spontaneous preterm by intrapartum care and increased surveillance of maternal health conditions during the three semesters could reduce IUFD cases.(21)In the case of previous IUFD particularly the unexplained one all the studies emphasized on the need of intensive ANC in order to decrease stillbirth incidence or at least provide the parents with explanation of the cause of fetus death. $(8,17)$

\section{Limitation:-}

The first one is the retrospective nature of the study which induce limitation in the availability of proper information and cause exclusion of adequate cases from the study. Secondly, the results were collected only from one health center (KAUH) andcouldn't generalize on other healthcarecenters in Jeddah.

\section{Conclusion:-}

In conclusion, fetus death is one of the most sadness and depressing events for both parents and the obstetrician, Despite considerable scientific progress in the field of health particularly Obstetrics and Gynecology, childbirth and neonatal care IUFD remains a significant proportion of fetus and neonates deaths, due to several factors (hypertension, Diabetes, maternal infections, obstetric hemorrhage). More educational programs need to be designed and implemented among the community to increase the level of awareness about the importance of antenatal care and its impact on reducing fetus death rate. 


\section{References:-}

1. Koshida S, Ono T, Tsuji S, Murakami T, Takahashi K."Recommendations for preventing stillbirth: a regional population-based study in Japan during 2007-2011".Tohoku J Exp Med. 2015;235(2):145-9.

2. Gizaw M, Molla M, Mekonnen W. "Trends and risk factors for neonatal mortality in Butajira District, South Central Ethiopia, (1987-2008): a prospective cohort study"

3. BMC Pregnancy Childbirth. 2014; 11:14:64.

4. Choudhary A, VineetaGuptaV. "Epidemiology of Intrauterine Fetal Deaths: A Study In Tertiary Referral Centre In UttarakhandIOSR". Journal of Dental and Medical Sciences (IOSR-JDMS) 2014; 13( 3 ): 03-06

5. Lawn JE, Lee AC, Kinney M, Sibley L, Carlo WA, Paul VK, Pattinson R, Darmstadt GL."Two million intrapartum-related stillbirths and neonatal deaths: where, why, and what can be done?".Int $\mathrm{J}$ GynaecolObstet 2009,107(Suppl 1):S5-S18. S19.

6. Huang DY, Usher RH, Kramer MS, Yang H, Morin L, Fretts RC. "Determinants of unexplained ante-partum fetal death". JObstetGynaecol2000; 95: 215-221.

7. Singh N, Pandey K, Gupta N, Arya AK, PratapC,Naik R: "A retrospective study of 296 cases of intra uterine fetal deaths at a tertiary care center in Kanpur, India". Int J ReprodContraceptObstetGynecol 2013, (2):141-146

8. Silver RM, Varner MW, Reddy U, Goldenberg R, Pinar H, Conway D, Bukowski R, Carpenter M, Hogue C, Willinger M, Dudley D, Saade G, Stoll B ."Work-up of stillbirth: a review of the evidence".. Am J Obstet Gynecol. 2007;196(5): 433-444

9. Lamia A. Shaaban LA, Al-Saleh RA, Alwafi BM , Al-RaddadRMi. "Associated risk factors with antepartum intra-uterine fetal death". Saudi Med J 2006; 27 (1): 76-79

10. Archibong EI, Sobande AA, Asindi AA. "Antenatal intrauterine fetal death; A prospective study in a tertiary hospital in Western Saudi Arabia".JObstet Gynaecol2003; 23: 170-173.

11. 10.Roxanne Beauclair R, Petro $G$ and Myer L. "The association between timing of initiation ofantenatal care and stillbirths: a retrospectivecohort study of pregnant women in Cape Town,South Africa ". BMC Pregnancy and Childbirth 2014; 14:204

12. 11. Yakoob MY, Lawn JE, Darmstadt GL, Bhutta ZA: Stillbirths. "Epidemiology, evidence, and priorities for action". SeminPerinatol $2010 ; 34(6): 387-394$.

13. BerhanY, BerhanA."A Meta-Analysis of Selected Maternal and Fetal Factors for Perinatal Mortality".Ethiop J Health Sci. 2014; 24(0 Suppl): 55-68.

14. Mutz-Dehbalaie I, Scheier M, Jerabek-Klestil S, Brantner C, Windbichler GH, Leitner H, Egle D, Ramoni A, Oberaigner W. "Perinatal mortality and advanced maternal age".GynecolObstet Invest. 2014;77(1):50-7.

15. Weng YH, Yang CY, Chiu YW. "Risk Assessment of Adverse Birth Outcomes in Relation to Maternal Age".PLoS One. 2014;9(12):e114843.

16. Siddiqui F,Lucy Kean Intrauterine K. "Intrauterine fetal death ". Obstetrics, Gynecology and reproductive Medicine. 2008; 19:1

17. Ditchfield AM, Desforges M, Mills TA, Glazier JD, Wareing M, Mynett K, Sibley CP and Greenwood SL. "Maternal obesity is associated with a reduction in placentaltaurine transporter activity". International Journal of Obesity .2015; 39: 557-564

18. Mohamed MS, ZahranKM, Mohamed HS,GalalH, Mustafa AM. " Pattern of glucose intolerance amongpregnant women with unexplained IUFD".Middle East Fertility Society Journal. 2015; 20, 43-47.

19. Kidron D, Bernheim J, Aviram R. "Placental findings contributing to fetal death, a study of 120 stillbirths between 23 and 40 weeks gestation".Placenta. 2009;30(8):700-4.

20. Unterscheider J, O’Donoghue K, Daly S, Michael P, Geary M, Kennelly MM, et al. "

21. Fetal growth restriction and the risk of perinatalmortality-case studies from the multicenter PORTO study".BMC Pregnancy Childbirth. 2014;14:63.

22. Gebhardt S, Oberholzer L. "Elective Delivery at Term after a Previous Unexplained Intra-Uterine Fetal Death: Audit of Delivery Outcome at Tygerberg Hospital, South Africa".PLoS One. 2015;10(6):e0130254.

23. Allanson ER, Muller M, Pattinson RC. "Causes of perinatal mortality and associated maternal complications in a South African province: challenges in predicting poor outcomes". BMC Pregnancy Childbirth. 2015;15:37. 